\title{
Is regional emergency management key to containing COVID-19? A comparison between the regional Italian models of Emilia-Romagna and Veneto
}

\author{
Roberta Troisi and Gaetano Alfano \\ Department of Political and Communication Science, University of Salerno, \\ Fisciano, Italy
}

\begin{abstract}
Purpose - This paper analyses emergency management in two regions of Italy - Emilia-Romagna and Veneto - in order (1) to understand whether they impact on the spread of local coronavirus disease 2019 (COVID-19) contagion and (2) evaluate which strategy works best.

Design/methodology/approach - A three-step method was developed consisting of (1) a regional incidence curve analysis; (2) a descriptive statistical analysis of the respective operational measures related to the COVID-19 curve stages; and (3) a dynamic Structural Equation Model.

Findings - The results show the effects of the models during the various stages of the local contagion, focussing both on the two individual regions and a comparison of the way they responded.

Practical implications - Three theoretical implications are highlighted: (1) Better results are not necessarily the outcome of increased expenditure; (2) The overall rigidity they both show does not work; (3) The decision to centralize was, to some extent, effective for both regions.

Originality/value - The article empirically tests the effectiveness of emergency management in tackling a single event. Instead of the widely-used normative approach, the authors adopted a descriptive one, which is not frequently discussed in the emergency management literature.
\end{abstract}

Keywords Regional emergency management, COVID-19, Coordination model, Centralized model,

Decentralized model

Paper type Research paper

\section{Introduction}

As with all disaster events, the coronavirus disease 2019 (COVID-19) outbreak has highlighted the key issue of emergency management for public agents. There are, however, substantial differences between traditional crises and the current health crisis: although both are exceptional situations, traditional crises are sufficiently predictable in terms of the temporal and spatial scale (Capano, 2020).

In contrast, COVID-19 can be defined as a "creeping crisis" characterized by the uncertainty of its temporal boundaries, which hinders rapid detection, and by the unforeseen changes during its lifespan that exacerbate the problems for crisis managers and politicians (Bernanke et al., 2019).

This situation leads to a worrying mix of urgency and deep uncertainty (Boin et al., 2020a, b), and thus represents a challenge of unprecedented complexity. Thus, the difference

(C) Roberta Troisi and Gaetano Alfano. Published by Emerald Publishing Limited. This article is published under the Creative Commons Attribution (CC BY 4.0) licence. Anyone may reproduce, distribute, translate and create derivative works of this article (for both commercial and non-commercial purposes), subject to full attribution to the original publication and authors. The full terms of this licence may be seen at http://creativecommons.org/licences/by/4.0/legalcode

Received 5 June 2021 Revised 22 September 2021 Accepted 26 October 2021
Regional emergency management 
IJPSM

35,2

196 between the characteristics of past crises and creeping should be projected in the different institutional responses (Boin et al., 2020a, b).

In terms of the spatial dimension, the creeping impact of the COVID-19 crisis differs markedly within countries and within regional/local governments. The evolution of the contagion is highly asymmetric within countries, showing different ways of developing before reaching its tipping point (Engström et al., 2021). As a consequence, crisis responses should be managed by those actors on the frontline in order to ensure the adoption of quick and appropriate decisions in each region (Scaparra and Church, 2012). On this line, most countries have experienced new joint management patterns between national and subnational governments, characterized by the coordination of the emergency powers required in these circumstances.

Thus, understanding the dynamics of the COVID-19 emergency requires a shift from how emergency management worked in the past to how it works today (Wolbers et al., 2018).

This study proposes an alternative descriptive approach, which focuses on how regional agents perform their functions in these challenging circumstances (Schakel et al., 2016). The two interrelated research objectives are, first, to analyse cases of Regional Emergency Management (REM) in order to understand whether they are able to curb the spread of local contagion. This approach is a specific short-term response whose sole aim is to mitigate the hazard. It is not based on tackling the underlying causes of vulnerability or broader longerterm recovery objectives aimed at returning the community to normal. Although it is linked to a creeping crisis, it therefore poses fewer measurement problems than the latter objectives whose long-term implications are still difficult to define. Second, a comparison of the mix of tools deployed by the regions to respond to COVID-19 is an important step in assessing the effectiveness of different policy designs, although strictly limited to the objective of reducing the spread of the disease (Wankhade, 2011).

The overall aim is to help policymakers improve local crisis management structures by drawing on lessons at the frontline. This can provide important contributions by examining (1) the key policy objectives; and (2) the operational measures, together with the types of agents involved and the coordination model deployed across the stage of a non-linear event.

The focus is on the Italian scenario from March to November 2020. Italy was the first European country to record a case of COVID-19 with a significant increase in the number of cases in just a few weeks. The response in Italy was mainly based on a central and regional "stop and go" strategy because the trend from March to November was characterized by two waves, as in most countries across the globe. The first, from March 2020, forced the central government to declare the longest lock-down ever experienced in Europe. A rebound of the epidemic was recorded in autumn. The second wave led the central government to develop a different strategy based on a greater differentiation between regions in terms of local contagion, giving subnational governments greater autonomy in their decisions than during the first wave.

Our analysis focuses on the two Italian regions of Veneto and Emilia-Romagna, and compares their REM during the two waves. These regions are similar in terms of the social indicators considered relevant in the spread of the contagion (age index, mean age, and epidemiological frameworks) [1]. The health-care indicators are also similar. The quality of their health-care systems is ranked in the top three among all Italian regions [2]. There are also similarities in their regional budgets over the last three years, with both recording a similar level of negative balance, and exhibiting an overall trend of improvement [3]. Finally, they are both geographically bounded by Lombardy, where the main outbreak of the epidemic in Italy originally occurred, and they also share a border. The remainder of this article is organized as follows: Section 2 reviews the Emergency Management frameworks; Section 3 provides the empirical analysis; Section 4 discusses the results; and Section 5 presents the conclusions. 


\section{The conceptual framework}

In this section, we describe the features of the emergency management adopted to tackle creeping crises, including the policies, key objectives and operational measures, focusing on those deployed to face COVID-19.

We then highlight the kind of agents, coordination mechanisms and decisions that characterize the emergency response, focusing on the two regions.

\subsection{Creeping crisis emergency management}

Creeping crises catch institutions unaware and are therefore rarely anticipated by prevention plans. Instead, policy responses are often strictly aimed at mitigating the sudden development of the crisis and therefore represent the framework of operational measures to face the non-linear path of these events (Handmer and Dovers, 2013).

Since reducing the impacts of a disaster is key, it is usually interpreted in multiple ways. Different key objectives may be achievable through different operational measures.

Multiple key objectives may be (1) conflicting: their trade-off is highlighted by the content of the operational measures (Karafili and Lupu, 2017) (2) hierarchical, mainly characterized by the different numbers of related tools available (3) balanced, depending on both the content and the number of operational measures (Glaus, 2021).

Many studies on crisis responses to tackle COVID-19 have underlined how policy responses that pose heavy limitations on basic liberties and public life were commonly prioritized, especially in the first wave of COVID-19. At the same time, it has been shown that over time, the policies across Europe have aimed to achieve a better balance between containing the virus and resuming ordinary activities (Toshkov et al., 2021). As discussed below, measures that curb the freedoms of the population gradually lose legitimacy among citizens (Schmidt, 2021).

Furthermore, the unforeseen pace of a creeping crisis should lead to different kinds of emergency responses with significant degrees of adaptability and flexibility, both at different times and at different levels.

A lack of timeliness and an inadequate response can extend the lifespan of the creeping crisis (Boin et al., 2020a).

The ability to adapt can also be due to place-based learning or to jurisdictions imitating each other: the ability to "experiment" or to gain lessons and insights from other places should depend on what represents the best cost-effective option.

The EU's initial reaction to the crisis was characterized by an immediate adaptability and contingent learning which increased in line with the intensity of change (Ladi and Tsarouhas, 2020). At the local level, policy imitation was recognized as influencing "stay-at-home" orders. Since the different policies are untested, governments copy each other in order to obtain the best solutions (Patterson, 2021).

Finally, another possible solution to complex crises is based on the "redundancy" strategy to deliver a quick response. This involves the provision of excess resources compared to its minimum requirement. Although it is not a cost-effective solution, it enables extensive uncertainties to be tackled by multiplying the quantity of tools and thus reinforcing each other (Weick and Sutcliffe, 2001). Studies on the adoption of health policies regarding COVID-19 show that redundancy has characterized the public health response to the COVID-19 crisis in democracies and decentralized states more than in centralized states and in autocracies with positive results particularly during the first wave (Shvetsova et al., 2020).

\subsection{Key agents and coordination mechanisms}

Tackling a complex health crisis by an immediate response may broaden the set of agents involved in addition to the institutional actors, since this kind of crisis can be better solved

\section{Regional emergency management}


IJPSM

35,2

through multi-actor participation (Jung et al., 2019). However, public agents remain the key subjects who are permanently at the core of management, while the other agents may be directly involved in decision-making or taking a peripheral role that may change according to the nature of the event (Robinson et al., 2013).

Decision-makers have been faced with the problem of health systems being overwhelmed, together with the unprecedented measures of social distancing and imposed quarantines. These measures can lead to social disorder and serious economic damage especially if prolonged (Boin et al., 2020a, b).

Moreover, many decisions have been made without full scientific evidence, characterized by divergent experts' opinions as in the case of the obligation of masks, school closures and currently, the vaccines administration (e.g. Brooks, 2020).

On the one hand, in many countries, a number of experts - particularly in the medical field - have been involved in policy-making. This is aimed at both achieving scientific legitimacy and strengthening the citizens' consensus (Wray et al., 2020)

On the other, a number of local agents have been involved in operational decisions and policy implementation. Their participation is explained both in terms of the effectiveness of the responses deployed and to gain citizens' consensus.

Efficiency is related to the kind of coordination mechanisms to support shared goals, and particularly the allocation of tasks and competencies across different levels of institutional actors together with non-institutional actors (Feldmann-Jensen et al., 2019).

Both central governments and regional/local governments had to take decisions about how to coordinate their emergency response systems in order to effectively reduce the spread of COVID-19 (Comfort et al., 2020). Managing the emergency involves choosing between centralized or decentralized decisions. According to the organizational literature, centralization is characterized by one decision-making public actor and execution down the ranks without any flexibility (Takeda and Helms, 2006). Its main advantage is the avoidance of decision paralysis, by implementing non-negotiated schema and pre-determined action plans.

On the other hand, decentralization focuses on a more adaptive response, in which the public agents are supplemented by further agents within a wider network aimed at ensuring adaptation to the changes imposed by uncertainty (Bracci et al., 2021). The choice between the models is rarely absolute though coordination mechanisms can follow one prevailing paradigm. Such prevalence is fundamental because it has led to different results in terms of "efficiency" in mitigating the COVID-19 impact both at the national and regional level. Kuhlmann et al. (2021) highlight that although France and Germany commonly adopted heavy personal restrictions to tackle COVID, they chose different governance arrangements. In France, the central government responded hierarchically, mainly adopting uniform measures that were both imposed and monitored, with better results during the first wave. By contrast, the response in Germany was characterized by a strong regional variance based on negotiations and coordinative efforts between local and regional actors.

\subsection{Key agents and coordination mechanisms in Emilia-Romagna and Veneto}

Focusing on the governance arrangements of Veneto and Emilia-Romagna, there were considerable differences both regarding the choice between centralization and decentralization and the way experts were involved.

During the three phases of COVID-19 examined in this study (see under, Section 2.2), the Veneto governance arrangements were characterized by a strong tendency to centralize both decisions related to public health objectives and health assistance.

At the core of the emergency system, there is "Azienda Zero" which is an agency of the Veneto Regional Department of Health. Under normal conditions, this agency plans, coordinates and checks the measures deployed by the local health districts at the second level 
of the rank. Specifically, Veneto implements an emergency plan already in its possession that provides for a Public Health Emergency Committee at two levels (strategic and operational). At the strategic level, a control room is led by the Health Department of the region and coordinated by Azienda Zero. At the operational level, there is an emergency team composed of the heads of the local health districts.

This is also an emergency decision-making model that is significantly legitimized thanks to the support of Professor Crisanti, an internationally renowned microbiologist. He is responsible for the improvement in the effectiveness of the swabs, and for the reliability and the speed of the results. He also recommended their being extended from the early stages of COVID-19 even to asymptomatic cases, contrary to the rest of the country. The general good results (see Section 3.2) led to the Regional Governor's re-election and to Veneto being considered as a model to emulate (Capano and Lippi, 2021). Furthermore, the reference arena is mainly institutional also in the implementation of the measures. Particularly in the first wave, Veneto essentially uses the civil protection or local police, without any involvement from outside the public actors, for example, for the distribution of masks, the medical equipment and the bulk of the logistic support.

The emergency model of Emilia-Romagna followed the ordinary healthcare model with a greater degree of decentralization and autonomy of the peripheral organs than the Veneto model. Emilia-Romagna in fact provides a health service system with one level being the regional department, and another level comprises three broad territorial large areas (TLA) including local departments, deputed to integrate and coordinate healthcare delivery, and also adopting strategical decisions. In this sense, there is no clear command chain. The Governor of Emilia-Romagna set up a task force to tackle COVID-19 composed of two regional councillors and two general managers of the health departments for the northern and the southern areas of the region.

A second task force with technical skills included nine members from the University Hospital of Bologna. This commission acts as an advisory board to support the decisions of the first commission. Finally, the acting commissioner, chosen from the political ranks, plays a liaison role between the two committees. This model tackles the emergency by balancing politics, institutions and knowledge (Berardi et al., 2020). Obtaining consensus from citizens is based on a multi-agent model with the inclusion of different social forces to counterbalance the lack of prominent figures recognized by the community as experts.

The choice of a greater participation also characterizes the implementation of the operational measures. Local nonprofit organizations are involved as affiliated, formal agents in formal plans to distribute masks and provide logistical support for the measures, together with teams from the department for civil protection [4].

\section{Empirical strategy}

A three-step method was used to assess the effects of the Regional Emergency Management (REM) cases on the incidence of COVID-19. This included (1) an initial study of the evolution of the COVID-19 endemic in Emilia-Romagna and Veneto, to illustrate the contagion trends; (2) a descriptive statistical analysis of the operational measures adopted within the respective Regional Emergency Management, related to the COVID-19 curve and incidence; and (3) a dynamic structural equation model aimed at observing the impact of REM strategies on the COVID-19 incidence over time.

\subsection{Data}

The data were obtained, classified and operationalized as follows: (1) The number of daily new cases was obtained from daily reports from the Ministry of the Interior. The number of daily new cases over 100,000 habitants indicates the incidence of the COVID-19, showing how 
IJPSM

35,2

200 the risk of contracting the disease within a population changes over time (Shields and Twycross, 2003). Avoiding contagion or reducing the incidence is typically the main aim of the emergency management of an infectious disease (Cenciarelli et al., 2015; Zinszer et al., 2015). (2) Regional ordinances and public health and healthcare plans as the main regional normative sources were used to classify the key REM objectives and the operational measures developed according to the contagion trend. These ordinances were taken from the national website of the Department of Civil Protection [5] which contains all the regional emergency acts in Italy, which are updated daily. By reading all the ordinances (45 for Emilia Romagna and 34 for Veneto) enacted during the reference period, the information obtained was then classified according to (1) the key objectives and their areas of application, (2) the operational measures and (3) when specified, how the agents involved were coordinated. Further details were sourced from regional and health ministry websites [6] together with local health publications [7].

The ordinance and health plan information by period of application was obtained in order to compare the course of the epidemic over that period and to identify the regions' responses as they moved through the non-sequential stages of the creeping crisis (two waves and an intermediate period of curve decline). A grounded theory approach in our analysis (Corbin and Strauss, 2008) was adopted. This approach is useful for dynamic processes and captures the features of the emergency responses together with the coordination between the activities and agents involved. The grounded data were systematically abstracted into more general patterns (Gioia et al., 2013). Table 1 depicts the above classification in detail.

\subsection{Empirical findings}

In this section, the main findings of the three-step analysis are described.

Step 1: In the analysis of the curves (Figure 1), the COVID-19 event is divided into three stages. The first stage, identified as the first wave, is from 24/02/2020 to 16/04/2020 and is characterized by an increasing number of COVID-19 positive cases. For both regions, the maximum number of infected was reached around 16 April. Figure 1 highlights how during this stage, the number of positive cases was higher in Emilia-Romagna than in Veneto. The second stage is from 17/04/2020 to $07 / 07 / 2020$ and is characterized by a decreasing number of COVID-19 positive cases for both regions with Veneto characterized by a faster reduction than Emilia-Romagna. Finally, the third stage, starting around 8July, shows a point of inflection of the curves, with a new increase in contagion. The increasing number of COVID-19 cases indicates the second wave of contagion. The graph shows how the number of positive cases was higher in Veneto than in Emilia-Romagna throughout the entire stage. In both regions, the number of positive cases increased rapidly starting from the first two weeks of October.

Step 2: The numbers of operational measures within the key objectives and the areas of application, related to the COVID-19 average, are briefly compared using the descriptive statistics, for each of the three identified stages, respectively, for both regions (Table 2). Descriptive statistics are also used to support the discussion.

The first stage (24/02/2020-16/04/2020) is characterized by the growth of the contagion curve, with a higher incidence for Emilia-Romagna (9.07) than Veneto (5.76). During the first wave, regional interventions were added to the general lockdown established by the central government on 9 March. Emilia-Romagna used a greater number of operational measures for all the general objectives, while Veneto carried out a higher number of swabs (4,236 daily tests vs Emilia-Romagna's 2,286) and favoured home-based care for patients $(4,150 \mathrm{vs} 3,730)$. The higher regional expenditure of Emilia-Romagna may explain these higher levels of deployment. 
Key objectives and area of application (codified 1-4)

Minimize the risk of transmission and mortality public health: (Code 1)

Identify, confirm and rapidly isolate Public health (Code 2)

Identify, confirm and rapidly isolate Health assistance: (Code 3)

Health assistance: improving the efficiency of health services

Health assistance (code 4)
Operational measures (values)
Distributed masks

Restrictions (personal, public sector and business)

Controls for the violation of COVID restrictions

Swabs carried out

Local quarantined areas

Home-based care patients

Hospitalizations

COVID medical equipment and other material resources

Recruitment of hospital staff average

Hospital network for transferring COVID patients
Daily number

Number

Daily number

Daily number Number

Daily number

Daily number

Monthly amount

in Euros

Number

$-$
Table 1. REM features

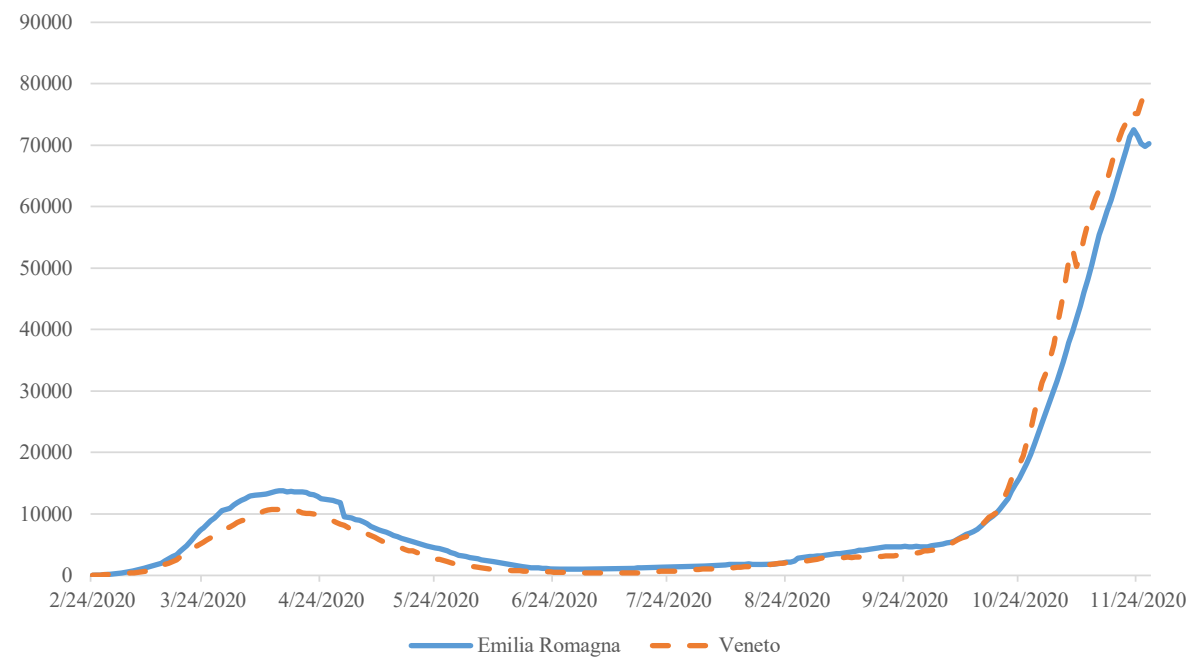

Figure 1.

Time evolution of the number of positive cases of COVID-19 endemic in EmiliaRomagna and Veneto

The second stage (17/04/2020-07/07/2020) shows a smaller incidence for both regions, with Veneto characterized by a faster reduction in the number of active cases than EmiliaRomagna. The central government gradually reduced the intensity of the lockdown during this stage. The regional interventions were thus directed toward partial control measures instead of the very restrictive measures adopted during the lockdown. These mainly public health measures focused on prohibiting gatherings, personal distancing and occupancy limits. In terms of measures related to public health objectives, the level of restrictive measures in Emilia-Romagna remained approximately the same, whereas restrictions increased in Veneto. The bulk of the operational measures increased substantially for both regions. In terms of the measures related to health assistance objectives, Veneto still prioritized the social isolation of people who tested positive for coronavirus, rather than their hospitalization. 


\section{IJPSM}

35,2

202

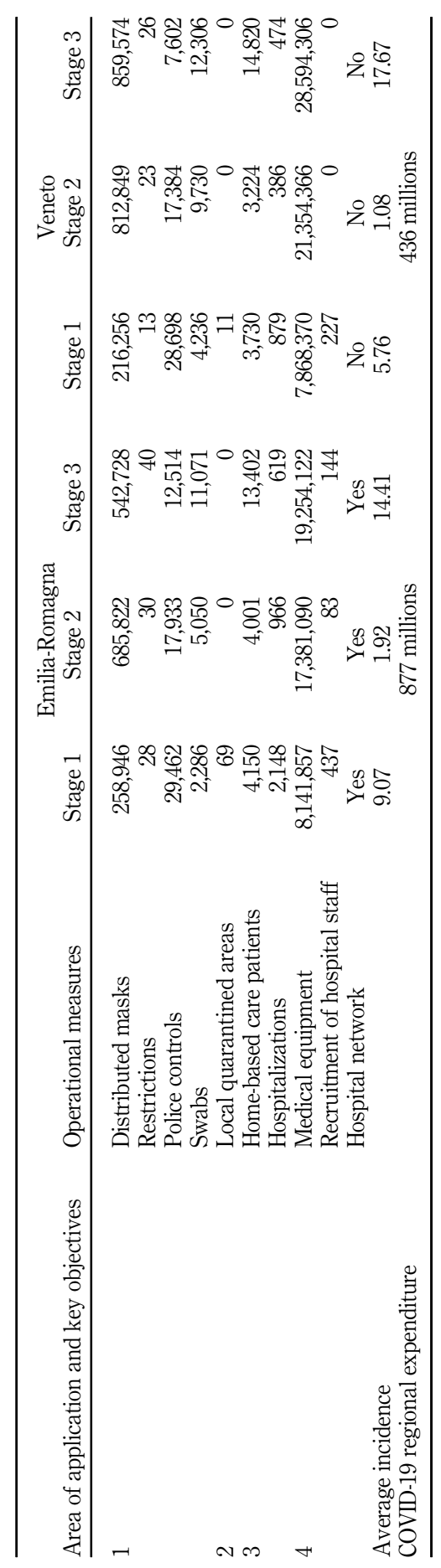

Table 2.

The numbers of operational measures 
In the third stage (08/07/2020-27/11/2020), the incidence of COVID-19 was higher in Veneto (17.67) than in Emilia-Romagna (14.41). Starting from 3 November, the central government decreed a new tier system according to the increasing degree of risk. Each region thus followed centralized restriction guidelines, which were effectively integrated at local levels both by adding new restrictions and making national restrictions more stringent. The two regions were considered peer for the degree of risk. In terms of public health, during this stage, most of the actions were similar to those of stage 2. Emilia-Romagna continued with the use of limitations, with an increase in restricting personal behaviour. Unlike in the previous stage, the expenditure on healthcare was higher in Emilia-Romagna. Regarding health assistance, keyobjective 3 was achieved in Emilia-Romagna with a greater number of home-based patients $(13,402)$ and less hospitalization than in previous phases $(619$, very close to Veneto). Veneto still demonstrated a greater focus on public health objectives with an increase in the number of swabs, and distribution of masks and medical equipment to hospitals.

Step 3: The third step in the analysis implemented a dynamic structural equation model (DSEM) to assess the impact of the two REM models on the incidence of COVID-19. As previously mentioned, the incidence provides information on how widespread the pandemic is in a given period. The model uses stochastic (Bayesian) differential equations for assessing continuous processes over time (see Driver et al., 2017). Analytically the model is written as

$$
d \eta_{i}(t)=\left(A \eta_{i}(t)+\xi_{i}+B z_{i}+M \chi_{i}(t)\right) d t+G d W_{i}(t)
$$

where $\eta_{i}(t)$ is the vector of the processes of interest, here being the incidence of COVID-19. The $A$ matrix is the drift matrix with auto-effect on the diagonal and cross-effect off the diagonal that characterizes the temporal relationship of the process. $\xi_{i}$ is a vector of random variables that corrects the model in the long run, $B$ is the effect matrix of the timeindependent predictors $z_{i}$ on the process $\eta_{i}(t) \cdot \chi_{i}(t)$ is the time-dependent variable. Finally, $W_{i}(t)$ is a Wiener process, which represents the stochastic error term in the relation.

The model considers the main effects of time-dependent and time-independent variables on the average level of COVID-19 incidence over time. The mean value of the temperature and the mean value of the humidity have been considered time-dependent variables (Rahman $e t$ al., 2020). Other works have found a significant relation between these variables and the spread of infections (Rahman et al., 2020). The REM adopted in the regions was considered as a time-independent variable. Based on the key objectives and the pattern of the operational measures, the REM adopted in Veneto was characterized by a greater focus on public health objectives, and the REM adopted in Emilia-Romagna was wide ranging, since the regional intervention better balances public health with health service measures. More specifically, the variable REM is operationalized as dichotomous assuming value one for Veneto's REM and 0 for Emilia-Romagna's REM. Four models were implemented: one considering the overall COVID-19 outbreak from March to November, the other three considering the three stages indicated above. The results are presented in Table 3.

The results show that during the first stage of the contagion (Model 1, March-April 2020), REM did not have a significant relation with the incidence of COVID-19. On the other hand, during the second stage (Model 2), a negative relationship was found between the incidence and the REM adopted (-0.397, CI [-0.440, -0.362$])$. Thus, during this second stage, Veneto's REM seems to better reduce the incidence of positive cases in the region. During the third stage, from July to November, the analysis shows a significant positive relation (2.482, CI $[2.179,2.815]$ for Model 3) between the incidence and the REM adopted. During this stage, the REM of Emilia-Romagna seems to be related to a lower incidence of the virus than the REM of Veneto. Finally, considering the overall period of investigation, Model 4 also shows a positive relationship between incidence and the REM adopted (1.684, CI [1.300, 2.052)]. 


\begin{tabular}{|c|c|c|c|c|c|c|}
\hline \multirow{6}{*}{$\begin{array}{l}\text { 1JPSM } \\
35,2\end{array}$} & & Variable & Mean & SD & $2.5 \%$ & $95 \%$ \\
\hline & Model 1 (stage 1) & Temperature & 0.028 & 0.054 & -0.078 & 0.129 \\
\hline & & Humidity & 0.007 & 0.009 & -0.010 & 0.026 \\
\hline & & REM & -1.088 & 0.810 & -2.865 & 0.248 \\
\hline & Model 2 (stage 2) & Temperature & 0.001 & 0.008 & -0.014 & 0.017 \\
\hline & & Humidity & 0.000 & 0.003 & -0.005 & 0.006 \\
\hline \multirow[t]{6}{*}{204} & & $\mathrm{REM}^{*}$ & -0.397 & 0.020 & -0.440 & -0.362 \\
\hline & Model 3 (stage 3) & Temperature* & -0.058 & 0.029 & -0.115 & -0.003 \\
\hline & & Humidity* & 0.026 & 0.010 & 0.006 & 0.046 \\
\hline & & $\mathrm{REM}^{*}$ & 2.482 & 0.162 & 2.179 & 2.815 \\
\hline & Model 4 (overall period) & Temperature $^{\circ}$ & -0.028 & 0.015 & -0.058 & 0.001 \\
\hline & & Humidity* & 0.012 & 0.005 & 0.002 & 0.022 \\
\hline \multirow{2}{*}{$\begin{array}{l}\text { Table } 3 . \\
\text { DSEM results }\end{array}$} & & $\mathrm{REM}^{*}$ & 1.684 & 0.193 & 1.300 & 2.052 \\
\hline & \multicolumn{6}{|c|}{ Note(s): Significance codes: ${ }^{*} p<0.05,{ }^{\circ} p<0.1$} \\
\hline
\end{tabular}

A negative relationship was found between temperature and incidence $(-0.058, \mathrm{CI}[-0.115$, $-0.003]$ for Model 3). This result is in line with other findings that show an increase in temperature curbing the spread of the virus. Moreover, a positive relation between humidity and incidence was found $(0.012, \mathrm{CI}[0.002,0.022]$ for Model 4$)$ also confirming the reduction in the incidence with a reduction in humidity (Rahman et al., 2020).

\section{Discussion}

In line with the empirical findings, this discussion is organized following the three stages of COVID-19 underlying the features of the two REM models.

With regard to the first stage of the COVID-19, there was a lower COVID-19 incidence in Veneto than in Emilia-Romagna. However, the DSEM results are not significant: probably the national lockdown during this stage likely had a greater effect on the spread of COVID-19 than the regional responses. Furthermore, the spontaneous action of agents (i.e. volunteers and citizens) may also have affected the incidence; however, the lack of official data prevents this from being included in this analysis.

The descriptive statistics in Table 2 show that the substantial differences between the two regional strategies reflect a difference in COVID-19 incidence. The overall response of EmiliaRomagna seems to reflect the balance characterized by the different agents in the two central task forces since it pursued all four key objectives and was supported by a greater regional expenditure. Furthermore, these objectives were pursued through many decentralized arrangements ranging from TLA decision-making regarding healthcare measures, such as hospitalizations and home-based care of patients, to the municipal management of the local quarantined areas and controls. However, governance strategies focused on coordinative efforts did not seem to slow down the spread of the virus, at least compared to the incidence in Veneto. It is very likely that the number of resources used together with the number of actors involved, including non-institutional actors made the response slow rather than flexible, especially due to the lack of previous experience.

The Veneto data indicate an overall response that is in contrast to the broad-based response developed by Emilia-Romagna. Veneto appeared to establish a hierarchical order in terms of key objectives and operational measures (Glaus, 2021), focusing on "identifying, confirming and rapidly isolating" (key-objective 2-3) both in terms of public health and health assistance through a greater number of swabs and a better ratio of home-based patient care/hospitalization. The strategy therefore has two characteristics: (1) strict subordination and clear chains of command ranging from the regional control room to the emergency team 
guaranteeing a straightforward, uniform response in line with a coordination model that had already been tested in ordinary conditions (Takeda and Helms, 2006), (2) it was influenced by Crisanti's expertise (see 2.2), turning into medical priorities in operational measures (Capano and Lippi, 2021).

The descriptive statistics highlight that this approach works well in such a scenario, since it is accompanied by a slower virus growth rate.

As for the declining stage of the contagion curve, the emergency management model shows a better reduction in infections in Veneto than in Emilia-Romagna and is significant according to the DSEM. The overall response of Emilia-Romagna appears to be in line with that of the previous stage. It still aims to balance public health and healthcare objectives with an average increase in the numbers of the operational measures following a redundancy strategy (Weick and Sutcliffe, 2001). The restrictions imposed in the ordinances, in line with the previous phase although less severe [8], are exceptions to the general increase. Thus, in the declining stage of COVID-19, Emilia-Romagna aimed at more acceptable limitations for its citizens, without entailing enormous sacrifices in terms of freedom. The goal was probably to achieve both compliance with the measures, which are difficult to obtain for extended periods of time, and the legitimacy of the decisions made (Schmidt,2021; Boin et al., 2020a, b).

Most of the operational measures were the same as in the previous phase with the only difference being in terms of the numbers of measures adopted. This is surprising because the model emphasizes decentralization, involving local agents in various capacities. A learning ability is expected from the crisis that is place-based with greater flexibility. Instead, the model is rigid since it does not show changes in strategies but only in the number of operational measures despite the new phase of the creeping crisis.

The model is further characterized by a discrepancy between the increase in the measures, which indicates a strategy of preparedness for a very likely and imminent second wave, and the reduction in limitations that appear to be oriented towards a slow return to normality. This could explain the slower decrease in COVID-19 incidence in this period.

Veneto also appears to continue with the same overall response as in the first phase, which is mainly focused on public health measures, as mentioned in Section 2.2, although massively increased. This rigidity could be due to the fact that the model is centralized and therefore has a low capacity to adapt to the crisis, and that the model enjoys the citizens' broad legitimacy of the decisions made (Wray et al., 2020). However, a slight change in perspective should be noted, although at a peripheral level, with the inclusion of some decentralized operational measures similarly to Emilia-Romagna. For example, greater leeway was given to municipalities and the implementation of operational tools also involved non-institutional agents. The strategies of the two regions demonstrate two main differences. Veneto does not consider the key-objective of hospital efficiency as a priority, thus maintaining its low ratio of hospitalized to home care assistance. The general limitations are also greater than in the previous period, particularly those that regulate citizens' behaviour. In essence, Veneto continued to keep its "guard up", without reducing its limitations, and counting on consensus regarding its choices that derives from the previous phase.

The third stage showed a faster growth in infections in Veneto compared to EmiliaRomagna, which was significant according to the DSEM. Furthermore, a significant relation was shown between climatic variables (temperature and humidity) and the spread of the virus.

Emilia-Romagna developed an overall response that was still balanced between public health and health assistance objectives, still characterized by redundancy in operational measures, which further increased compared to the previous phases. However, unlike the previous stages, it also included an increase in restrictions on citizens. Although the model is still decentralized, an important centralized decision was added: the regional health plan was jointly adopted by the two task forces, thus, reducing the number of decisions to be taken at a peripheral level. 
IJPSM

35,2

206

Veneto also re-instigated its response strategy developed during the first wave which was focused on public health actions with the specific measures increased in a redundant manner (numbers of masks and swabs). The overall response was insufficient to slow the rate of the contagion curve, possibly because Veneto did not significantly invest in keyobjective 4 (health service improvement), but focused on increased purchasing of technical equipment. In addition, the number of restrictions was lower than in Emilia-Romagna probably in order to avoid excessive restrictions for citizens which had been on-going for months.

This was not only a matter of numbers, as in this scenario, the rules of conduct established in the national plan were significantly integrated within local measures, and thus played a central role. To some extent, the management of the response to the second wave was partial. There was a gap between the operational measures aimed at tackling the crisis and the ordinances that were probably insufficient to cope with the new outbreak of the contagion. Considering the regional expenditure (see Table 2), the model was probably not economically viable in terms of a prolonged redundancy approach, nor flexible enough for its centralization to learn quickly from a sudden change in scenario that the creeping crisis has shown.

The following tables summarize the evolution of the two regional management models. Specifically, Table 4 shows the evolution of governance arrangements, and Table 5 depicts the trends in the number of operational measures adopted during the three stages.

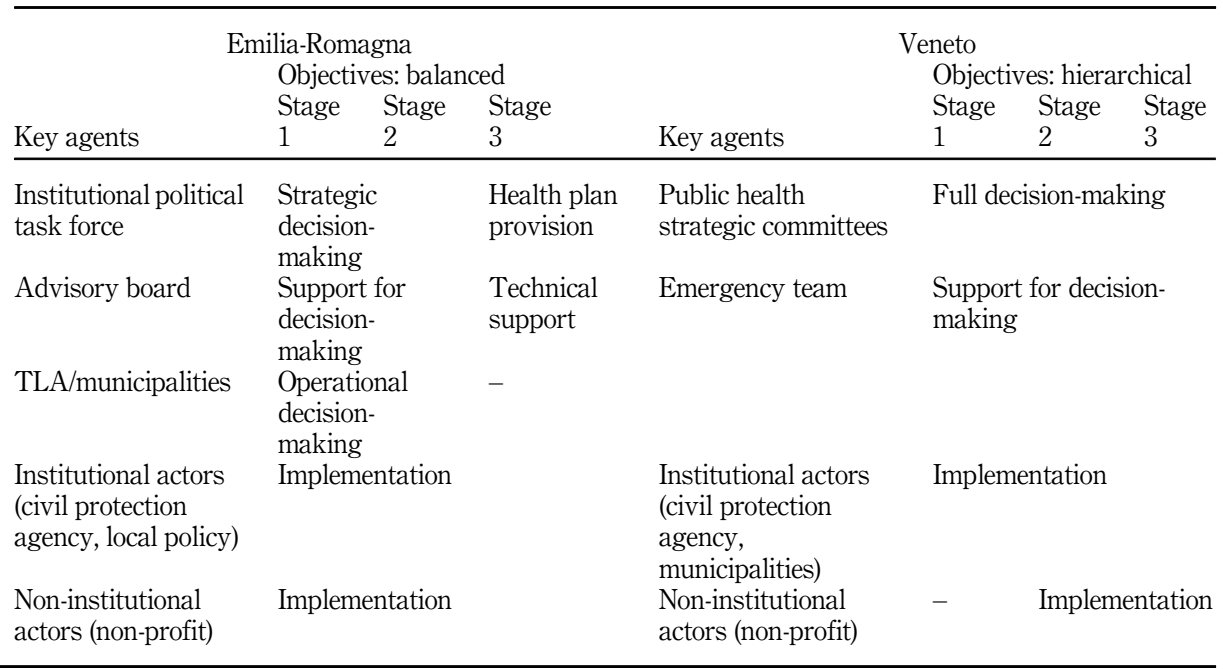

Table 5.

The operational measures during the COVID-19 pandemic: three stages

\begin{tabular}{|c|c|c|c|c|c|c|c|}
\hline & \multicolumn{3}{|c|}{ Restrictions } & \multirow[t]{2}{*}{ Other measures } & \multirow[b]{2}{*}{ Stage 1} & \multirow[b]{2}{*}{ Stage 2} & \multirow[b]{2}{*}{ Stage 3} \\
\hline & Stage 1 & Stage 2 & Stage 3 & & & & \\
\hline Emilia-Romagna & 28 & +2 & +10 & & & $+25 \%$ & $+42 \%$ \\
\hline \multirow[t]{2}{*}{ Veneto } & 13 & +10 & +3 & $\begin{array}{l}\text { Hierarchical objective } \\
\text { related }\end{array}$ & & $+66 \%$ & $+38 \%$ \\
\hline & & & & $\begin{array}{l}\text { Non-hierarchical } \\
\text { objective related }\end{array}$ & & $+32 \%$ & $+19 \%$ \\
\hline
\end{tabular}




\section{Conclusions}

This analysis had two research objectives: first, to understand how the analysed REM models influenced the spread of the local contagion and second, to assess the general strategies behind regional emergency patterns. We focused on two regions in Italy through a grounded analysis, which is appropriate for a unique event. This involves an assessment of the sequencing of instruments used to tackle COVID-19, rather than a fully theoretical approach. The REMs of the Veneto and Emilia-Romagna regions are focused on and compared. The results of our analysis showed that the location and design of emergency management models are important. The regional variations in the effects of COVID-19 require a local/ regional approach to emergency management, as this addresses specific local needs and differences in the contagion. The empirical findings support these arguments.

When comparing the REM models with the incidence of contagion, response decisions were shown to be implemented at different levels of average incidence. The descriptive statistics indicate that the measures had different levels of influence through the local contagion stages, both within a single region and when comparing the two overall responses. In addition, the DSEM demonstrates the significance of the measures on the incidence of COVID-19. The second objective was addressed by examining the general strategies that determine the regional emergency patterns. We then evaluated what strategy works well. This can teach important practical lessons about how to cope with a unique emergency in terms of prioritizing key-objectives, the related operational measures and their coordination dynamics. It represents the main contribution of our analysis. The REM of Veneto was shown to work well in two phases as a mix of centralisation/legitimisation. Veneto adopted faster responses, mainly moving in an institutional arena, thus favouring coordination across ranks according to the logics of the command chain. At the same time, it took advantage of the citizens' legitimacy in adopting a set of choices that increasingly restricted personal freedom during the first two phases. In contrast, the REM of Emilia, based on decentralization/multiagent contributions did not seem to curb the spread of COVID-19 during the same two stages. The pursuit of a set of objectives equally supported in terms of resources seemed to achieve less effective results. Furthermore, the employment of a multi-agent model to take advantage of citizens' consensus by extending the involved actors turned into a disadvantage given the lack of previous experience.

In the last phase, however, the Emilia-Romagna model worked well. This seems to be the most convincing answer to COVID-19: it showed a good degree of adaptability to the nonsequential course of the event, making more decisive changes in governance arrangements and thus mitigating the rigidity of the previous phases. The provision of a regional task force health plan turned the decentralized model into a hybrid where the prevailing network structure went hand in hand with a hierarchical component. This indicates a partial imitation of the Veneto model that better managed the simultaneous increase in operational measures thanks to the speeding up of the decision-making process.

Three theoretical implications can be highlighted: (1) Better results are not necessarily the outcome of increased expenditure. Veneto spent less but appeared to manage the two phases better. This confirms that adequate strategies and appropriate objectives can make a difference. (2) Rigidity does not work. The fixed content of the two REM models worked in alternate phases, thus demonstrating the need for flexible strategies. (3) When both regions operated in a centralized way, the decision-making was, to some extent, effective.

Finally, this analysis has some limitations. First, only two regions were investigated, which prevents the findings from being generalizable. Due to the nature of this pandemic, there was a different course of events in different countries and in different regions of the same country. Thus, regional strategies cannot represent a general solution by definition, as they are place-based; however, they can offer some suggestions as to how to adapt to different contexts. Second, we did not consider the informal voluntary action taken by individuals and

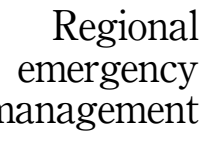

207 
IJPSM

35,2

groups which is recognized as an important resource in emergency responses, particularly in the mitigation stage. However, these limitations highlight possible future research directions. Extending the focus from a national to international scenario as well as widening the spectrum of actors could also offer a valuable contribution.

\section{Notes}

1. ottomilacensus.istat.it/, http://www.salute.gov.it/

2. http://www.salute.gov.it/portale/lea/

3. https://www.corteconti.it/Download?id=f900afd4-5f07-4a4b-81a1-273e14a4456a

4. https://sociale.regione.emilia-romagna.it/terzo-settore/approfondimenti/report-csv-emilia-romagnaservizi-emergenza-coronavirus.pdf

5. http://www.regioni.it/protezione-civile/2020/11/20/coronavirus-tabella-relativa-alle-leggi-e-alleordinanze-regionali-aggiornata-al-20-11-2020-608461/

6. https://www.regione.emilia-romagna.it/coronavirus/norme, https://www.regione.veneto.it/articledetail?articleId=4275256, https://www.regione.veneto.it/web/protezione-civile/corona-virus, http:// www.protezionecivile.gov.it/

7. e.g. http://www.quotidianosanita.it/emilia_romagna/, http://www.quotidianosanita.it/veneto/

8. By reading the ordinances, the restrictions are partial and organized according to three main criteria: time slots, type of days (weekdays/holidays), type of activity.

\section{References}

Berardi, C., Antonini, M., Genie, M.G., Cotugno, G., Lanteri, A., Melia, A. and Paolucci, F. (2020), "The COVID-19 pandemic in Italy: policy and technology impact on health and non-health outcomes", Health Policy and Technology, Vol. 9 No. 4, pp. 454-487, doi: 10.1016/j.hlpt.2020.08.019.

Bernanke, B.S., Geithner, T.F. and Paulson, H.M. (2019), Firefighting: The Financial Crisis and Its Lessons, Penguin Books, London.

Boin, A., Ekengren, M. and Rhinard, M. (2020a), "Hiding in plain sight: conceptualizing the creeping crisis", Risk, Hazards and Crisis in Public Policy, Vol. 11 No. 2, pp. 116-138, doi: 10.1002/rhc3.12193.

Boin, A., Lodge, M. and Luesink, M. (2020b), "Learning from the COVID-19 crisis: an initial analysis of national responses", Policy Design and Practice, Vol. 3 No. 3, pp. 189-204, doi: 10.1080/25741292. 2020.1823670.

Bracci, E., Tallaki, M., Gobbo, G. and Papi, L. (2021), "Risk management in the public sector: a structured literature review”, International Journal of Public Sector Management, Vol. 34 No. 2, doi: 10.1108/IJPSM-02-2020-0049.

Brooks, B.. (2020), "Like the flu? Trump's coronavirus messaging confuses public, pandemic researchers say", Reuters, 13 March, available at: https://www.reuters.com/article/us-healthcoronavirusmixed-messages/like-the-flu-trumps-coronavirus-messaging-confuses-publicpandemicresearchers-say-idUSKBN2102G.

Capano, G. (2020), "Policy design and state capacity in the COVID-19 emergency in Italy: if you are not prepared for the (un)expected, you can be only what you already are", Policy and Society, Vol. 39 No. 3, pp. 326-344, doi: 10.1080/14494035.2020.1783790.

Capano, G. and Lippi, A. (2021), "Decentralization, policy capacities, and varieties of first health response to the COVID-19 outbreak: evidence from three regions in Italy", Journal of European Public Policy, Vol. 28 No. 8, pp. 1-22, doi: 10.1080/13501763.2021.1942156.

Cenciarelli, O., Pietropaoli, S., Malizia, A., Carestia, M., D’Amico, F., Sassolini, A., Di Giovanni, D., Rea, S., Gabbarini, V., Tamburrini, A., Palombi, L., Belecci, C. and Gaudio, P. (2015), "Ebola virus 
disease 2013-2014 outbreak in West Africa: an analysis of the epidemic spread and response", International Journal of Microbiology. doi: 10.1155/2015/769121.

Comfort, L.K., Kapucu, N., Ko, K., Menoni, S. and Siciliano, M. (2020), "Crisis decision-making on a global scale: transition from cognition to collective action under threat of COVID-19", Public Administration Review, Vol. 80 No. 4, pp. 616-622, doi: 10.1111/puar.13252.

Corbin, J. and Strauss, A. (2008), "Strategies for qualitative data analysis", in Basics of Qualitative Research. Techniques and Procedures for Developing Grounded Theory, Vol. 3. doi: 10.4135/ 9781452230153.

Driver, Charles C., Oud, Johan H.L. and Voelkle, Manuel C. (2017), "Continuous time structural equation modeling with R package ctsem”, Journal of Statistical Software, Vol. 88 No. 5, doi: 10. 18637/jss.v077.i05.

Engström, A., Luesink, M. and Boin, A. (2021), "From creeping to full-blown crisis: lessons from the Dutch and Swedish response to COVID-19", in Understanding the Creeping Crisis, pp. 105-130.

Feldmann-Jensen, S., Jensen, S., Smith, S.M. and Vigneaux, G. (2019), "The next generation core competencies for emergency management”, Journal of Emergency Management, Vol. 17 No. 1, pp. 17-25, doi: 10.5055/jem.2019.0393.

Gioia, D.A., Corley, K.G. and Hamilton, A.L. (2013), "Seeking qualitative rigor in inductive research: notes on the Gioia methodology", Organizational Research Methods, Vol. 16 No. 1, pp. 15-31, doi: $10.1177 / 1094428112452151$.

Glaus, A. (2021), "Politics of flood risk management in Switzerland: political feasibility of instrument mixes", Environmental Policy and Governance, Vol. 31 No. 5, doi: 10.1002/eet.1940.

Handmer, J. and Dovers, S. (2013), Handbook of Disaster Policies and Institutions: Improving Emergency Management and Climate Change Adaptation, Routledge, London.

Jung, K., Song, M. and Park, H.J. (2019), "The dynamics of an Interorganizational emergency management network: interdependent and independent risk hypotheses", Public Administration Review, Vol. 79 No. 2, pp. 225-235, doi: 10.1111/puar.12993.

Karafili, E. and Lupu, E.C. (2017), "Enabling data sharing in contextual environments: policy representation and analysis", Proceedings of the 22Nd ACM on Symposium on Access Control Models and Technologies, pp. 231-238. doi: 10.1145/3078861.3078876.

Kuhlmann, S., Hellström, M., Ramberg, U. and Reiter, R. (2021), "Tracing divergence in crisis governance: responses to the COVID-19 pandemic in France, Germany and Sweden compared", International Review of Administrative Sciences, Vol. 87 No. 3, doi: 10.1177/0020852320979359.

Ladi, S. and Tsarouhas, D. (2020), "EU economic governance and covid-19: policy learning and windows of opportunity", Journal of European Integration, Vol. 42 No. 8, pp. 1041-1056, doi: 10. 1080/07036337.2020.1852231.

Patterson, S. (2021), "The politics of pandemics: the effect of stay-at-home orders on COVID-19 mitigation", State Politics and Policy Quarterly. doi: 10.1017/spq.2021.14.

Rahman, M.A., Zaman, N., Asyhari, A.T., Al-Turjman, F., Bhuiyan, Z.A.B. and Zolkipli, M.F. (2020), "Data-driven dynamic clustering framework for mitigating the adverse economic impact of Covid-19 lockdown practices", Sustainable Cities and Society, Vol. 62, doi: 10.1016/j.scs.2020. 102372.

Robinson, S.E., Eller, W.S., Gall, M. and Gerber, B.J. (2013), "The core and periphery of emergency management networks", Public Management Review, Vol. 15 No. 3, pp. 344-362, doi: 10.1080/ 14719037.2013.769849.

Scaparra, M.P. and Church, R. (2012), "Protecting supply systems to mitigate potential disaster: a model to fortify capacitated facilities", International Regional Science Review, Vol. 35 No. 2, pp. 188-210, doi: 10.1177/0160017611435357.

Schakel, J.K., van Fenema, P. and Faraj, S. (2016), "Shots fired! Switching between practices in police work”, Organization Science, Vol. 27 No. 2, pp. 391-410, doi: 10.1287/orsc.2016.1048. 
IJPSM

35,2

Schmidt, V.A. (2021), "European emergency politics and the question of legitimacy", Journal of European Public Policy, pp. 1-15, doi: 10.1080/13501763.2021.1916061.

Shields, L. and Twycross, A. (2003), "The difference between incidence and prevalence: this paper is one of a series of short papers on aspects of research by Linda Shields and Alison Twycross", Paediatric Nursing, Vol. 15 No. 7, pp. 50-51, doi: 10.7748/paed.15.7.50.s31.

Shvetsova, O., Zhirnov, A., VanDusky-Allen, J., Adeel, A.B., Catalano, M., Catalano, O. and Zhao, T. (2020), "Institutional origins of protective COVID-19 public health policy responses: informational and authority redundancies and policy stringency", Journal of Political Institutions and Political Economy, Vol. 1 No. 4, pp. 585-613, doi: 10.1561/113.00000023.

Takeda, M.B. and Helms, M.M. (2006), “Bureaucracy, meet catastrophe': analysis of Hurricane Katrina relief efforts and their implications for emergency response governance”, International Journal of Public Sector Management, Vol. 19 No. 4, doi: 10.1108/09513550610669211.

Toshkov, D., Carroll, B. and Yesilkagit, K. (2021), "Government capacity, societal trust or party preferences: what accounts for the variety of national policy responses to the COVID-19 pandemic in Europe?”, Journal of European Public Policy, pp. 1-20, doi: 10.1080/13501763.2021. 1928270.

Wankhade, P. (2011), "Performance measurement and the UK emergency ambulance service: unintended consequences of the ambulance response time targets", International Journal of Public Sector Management, Vol. 24 No. 5, pp. 384-402, doi: 10.1108/09513551111147132.

Weick, K.E. and Sutcliffe, K.M. (2001), Managing the Unexpected, Vol. 9, Jossey-Bass, San Francisco.

Wolbers, J., Boersma, K. and Groenewegen, P. (2018), "Introducing a fragmentation perspective on coordination in crisis management”, Organization Studies, Vol. 39 No. 11, pp. 1521-1546, doi: 10. 1177/0170840617717095.

Wray, A., Fleming, J. and Gilliland, J. (2020), "The public realm during public health emergencies: exploring local level responses to the COVID-19 pandemic", Cities and Health, Vol. Special Issue: COVID-19, pp. 1-4, doi: 10.1080/23748834.2020.1790260.

Zinszer, K., Morrison, K., Anema, A., Majumder, M.S. and Brownstein, J.S. (2015), "The velocity of Ebola spread in parts of West Africa", The Lancet Infectious Diseases, Vol. 15 No. 9, pp. 1005-1007, doi: 10.1016/S1473-3099(15)00234-0.

\section{Corresponding author}

Gaetano Alfano can be contacted at: galfano@unisa.it

For instructions on how to order reprints of this article, please visit our website:

www.emeraldgrouppublishing.com/licensing/reprints.htm

Or contact us for further details: permissions@emeraldinsight.com 